\title{
Suicides in psychiatric in-patients: what are we doing wrong?
}

\author{
DIEGO DE LEO and JERNEJA SVETICIC
}

\begin{abstract}
Given the uncontested role of psychiatric illnesses in both fatal and non-fatal suicidal behaviours, efforts are continuously made in improving mental health care provision. In cases of severe mental disorder, when intensified treatment protocols and continuous supervision are required due to individual's impaired emotional, cognitive and social functioning (including danger to self and others), psychiatric hospitalisation is warranted. However, to date there is no convincing evidence that in-patient care prevents suicide. In fact, quite paradoxically, both admissions to a psychiatric ward and recent discharge from it have been found to increase risk for suicidal behaviours. What elements in the chain of well-intentioned approaches to treating psychiatric illness and suicidality fail to protect this vulnerable population is still unclear. The same holds true for the identifications of factors that may increase the risk for suicide. This editorial discusses current knowledge on this subject, proposing strategies that might improve prevention.

Declaration of Interest: None.
\end{abstract}

\section{STRONG, YET INSUFFICIENTLY UNDERSTOOD LINKS BETWEEN MENTAL DISORDERS AND SUICIDE}

Mental and behavioural disorders affect more than $25 \%$ of all people worldwide at some time during their lives, and are present at any point in time in about $10 \%$ of the population (Wittchen \& Jacobi, 2005; World Health Organisation, 2001). Furthermore, in recent decades, the burden of disease due to mental health problems has been growing with the greatest burden attributed to unipolar and bipolar affective disorders, substance abuse, schizophrenia, and dementia (Mathers \& Loncar, 2006).

In the Diagnostic and Statistical Manual of Mental Disorders (DSM-IV) (American Psychiatric Association, 1994), suicidal thoughts and/or self-harming behaviour are included as symptoms defining only two psychiatric disorders, namely borderline personality disorder and depressive disorders. However, all mental disorders have been found to carry an elevated risk of premature death, from both natural and unnatural causes (Tidemalm et al., 2008), with diagnoses of affective disorders, substancerelated disorders, and schizophrenia being the strongest

Address for correspondence: Professor D. de Leo, Australian Institute for Suicide Research and Prevention, WHO Collaborating Centre for Research and Training in Suicide Prevention, and National Centre of Excellence in Suicide Prevention, Mt Gravatt campus, Griffith University, Griffith, QLD 4122 (Australia).

Fax: +61-7-3735.3450 risk factors for suicide (Harris \& Barraclough, 1997), and psychiatric co-morbidity increasing this risk even further (Tanney, 2000). Studies indicate that between $71 \%$ and $99 \%$ of suicides in all age groups have a diagnosis of psychiatric disorder (Cavanagh et al., 2003; ArsenaultLapierre et al., 2004), with this percentage reaching almost $100 \%$ in the in-patient suicide population (Bertolote et al., 2004).

The ways in which psychopathology affects suicidal behaviour has been the subject of much debate; yet, the relationship between the two phenomena and the related implications for suicide prevention remain insufficiently understood (Bertolote et al., 2003; 2004). Psychiatric disorders alone are not sufficient determinants of suicide, with other factors, including the availability and quality of mental health services, playing a very important role. However, under-provision of resources constitutes the most important barrier to effective mental health care, even in the highest-income countries, with most mentally disordered people receiving no effective care (Wittchen \& Jacobi, 2005; Saxena et al., 2007). For example, Luoma et al. (2002), in their review of studies on last contact with medical services among suicide victims, found that while about half of cases saw a primary care provider within one month from suicide, the percentage of contacts with mental health service was only $19 \%$, and about $32 \%$ in the year before suicide. Hence, improvements in the recognition and treatment of mental disorders remain a pivotal element of suicide prevention strategies worldwide (Bertolote et al., 2003). 


\section{IS HOSPITALISATION ALWAYS THE RIGHT SOLUTION?}

Thornicroft \& Tansella (2004) describe in their 'sequential stepped care model' that both community and hospital services are necessary for a well balanced mental health system. However, as acute in-patient care absorbs most of the mental health budget, availability of hospital beds for psychiatric population varies greatly, and is of particular concern in developing countries. While there is still discussion surrounding the effectiveness of psychiatric hospital care versus community-based treatment often in the context of growing de-institutionalisation in the developed world (Pirkola et al., 2007; Saxena et al., 2007) -, there seems to be general consensus that highintensity care in hospital units is nevertheless required for persons with severe psychiatric conditions and those presenting a risk to harm themselves or others (Mehlum, 2009). For example, Goldberg et al. (2007) found that hospitalisations occurred in $70 \%$ of suicidal persons presenting to psychiatric emergency services, and were associated with a diagnosis of psychosis, history of attempted suicide and presence of a suicidal plan.

However, available knowledge does not allow us to predict suicide with any degree of accuracy, even within a recognized high-risk sample of in-patients (Paris, 2007). Almost 20 years ago, Van Egmond \& Diekstra (1990) gloomily observed that research in suicide prediction has made little progress over the previous 25 years, and whilst several measurements of intent and risk have since then been developed, they did not prove any more efficient in predicting suicide than clinical evaluation (Mehlum, 2009). The study of sub-syndromal manifestations of specific mental disorder might have significant implications for future improvements in detecting suicide risk (Fergusson et al., 2005), particularly in light of the recent findings from the WHO World Mental Health Survey showing that only about half of people who had seriously considered killing themselves or made an attempt reported lifetime history of a mental disorder meeting the DSM-IV criteria (Nock et al., 2009).

In the absence of reliable tools for recognition of suicide risk, clinicians often either display insufficient concern for the safety of the patient, undervaluing the dangerousness of the situation, or use excessive caution, overestimating the actual suicidality, violating patient's rights and placing an unnecessary burden on mental health budget (Wingate et al., 2004). Paris (2007) maintains that the latter picture is driven by 'the rule of fear' a number of patients get admitted because of clinician's anxiety they would kill themselves and not because the hospitalisation would in fact be the most effective treatment approach (in practice, doctors obey to the 'better safe than sorry' principle). Paris further argues that while many patients with acute suicidality do benefit from a protective/restrictive hospital environment as a temporary expedient, admission of chronically suicidal patients is often counterproductive and should be in majority of cases replaced by out-patient settings (Paris, 2007). Escalating suicidality resulting from hospital admissions has been particularly observed in patients with borderline personality disorders (Williams, 1998).

To date, little systematic data collection has been done to evaluate clinical outcomes of in-patient treatments (Gowers \& Rowlands, 2005). Ethical restraints prevent conduction of studies involving acutely suicidal subjects or random allocation to different treatment settings of patients requiring psychiatric hospitalisation. After all, access to needed health care is a basic human right, with the decision on the type of care relying on medical professional's deliberation. Rates of involuntary admission vary depending on different legislations (Salize \& Dressing, 2004), and are strongly related to the availability of alternative forms of care (Lorant et al., 2007). Being male (Salize \& Dressing, 2004), having poor social support and belonging to a minority ethnicity group are characteristics that have been found to increase the likelihood of compulsory admissions (Webber \& Huxley, 2004), which usually involve longer hospital stays than those happening on a voluntary basis (Kaltiala-Heino, 2009).

In addition, given the high level of stigmatization embedded to mental disorders (Mann \& Himelein, 2004), the experience of psychiatric admission is often perceived as threatening and depersonalizing, especially when the admission is involuntary (Jones \& Crossley, 2008). In some mentally ill people, feelings of shame and personal failure have been noted to develop into a sense of internalized stigma, which can further influence patient's self-concealment and social alienation, and increase hostility towards self or others (Ritsher \& Phelan, 2004). The ward atmosphere has been found to be significantly related to the level of patients' satisfaction with treatment and, at least on short-term, objective treatment efficiency, such as reduction of symptoms and shortened length of stay (Holcomb et al., 1998; Jones \& Crossley, 2008). In Sweden, Traskman-Bendz \& Sunnqvist (2009) reported of a specialized unit for suicidal cases where a specifically structured management of patients, based on an empathetic and non-judgmental environment, has lead to better treatment outcomes. However, it is unclear whether the treatment environment

Epidemiologia e Psichiatria Sociale, 19, 1, 2010 
can in itself be therapeutic or if it only constitutes as a prerequisite to attaining positive outcomes (Eklund, 1996). Suicides have been reported to happen more frequently when the therapeutic alliance breaks down, a phenomenon described by Morgan \& Priest (1991) as 'malignant alienation', commonly found in patients with recurrent relapses and resistance to treatment, and perceived by staff as manipulative, provocative, unreasonable, over-dependent and feigning disability (Huband \& Tantam, 2000).

For several decades, sociological studies have been warning of the hazards related to labelling persons as mentally ill. For example, a renowned paper by Rosenhan (1973), On being sane in insane places, described how admitted patients are automatically perceived as mentally ill by staff members regardless of their actual, if at all present, psychiatric diagnosis. "I don't belong here with these crazy people", a statement from a patient expressing discontent when placed in a psychiatric ward alongside patients with severe mental disorders, exemplifies the above situation, as reported by Simon \& Gutheil (2009). Välimäki et al. (2001) observed that deprivation of liberty is frequently experienced by psychiatric patients in Finland, raising concerns on the paternalistic approach of many psychiatrists, especially when dealing with involuntary treatment patients, with doctors' attention mostly focused on psychotropic treatments rather than on the patient's actual needs.

\section{THE INTRODUCTION OF 'SENTINEL EVENTS'}

Self-harming behaviours in psychiatric patients remain a major concern in any psychiatric hospital setting. Apart from discussions on de-institutionalisation consequences, reductions in psychiatric beds in hospital wards (with admissions reserved for most severely ill patients) continues to generate debate on the possible impact on number of suicide fatalities (Johannessen et al., 2009; Lieberman et al., 2004). Combs \& Romm (2007) reported that suicide rates of psychiatric in-patients in different countries range from 100 to 400 per 100,000 admissions. An overview of suicide statistics in psychiatric hospitals in various countries showed an increasing trend of rates of suicides among in-patients since mid 1900s (Wolfersdorf, 2000; Cassells et al., 2005); however, a more recent report by Kapur et al. (2006) suggested the opposite. Either way, it should be noted that comprehensive assessments of prevalence of in-patient suicides are often hampered by inaccurate statistics and inadequate investigations following these events (Blain \& Donaldson, 1995). For example,
Powell et al. (2000) in their study of 97 in-patient suicides found that only $54 \%$ of cases were assigned a coroner's verdict of suicide, while remaining cases received an 'open verdict'. Traditionally, both practitioners and hospitals have been reluctant to report such events for fears of litigation and adverse publicity, but the introduction of reviewed policies surrounding investigations of so-called 'sentinel events' aims to improve these recordings (Fung et al., 2008). The Joint Commission on Accreditation of Healthcare Organisation (JCAHO)(2009) defines a sentinel event as an unexpected occurrence involving death or serious physical or psychological injury, or the risk thereof, which includes suicides of any patients receiving care, treatment and services in a staffed around-the-clock setting or within 72 hours after discharge (Joint Commission on Accreditation of Healthcare Organization, 2009). However, whilst one should not confuse the meaning of 'sentinel event' with 'medical error' (because not all sentinel events occur due to an error), they commonly reflect hospital process deficiencies resulting in unnecessary outcomes for patients, and as such should signal the need for immediate response and investigation ( Joint Commission on Accreditation of Healthcare Organization, 2009). In 2009, the JCAHO reported that since its introduction in 1995, suicide has been the second most reported sentinel event in the US (after wrong-site surgery), accounting for about $12 \%$ of all records, and with a marked increase in recent years. Once a sentinel event occurs, the organisation is required to perform a root-cause analysis, reviewing alteration in performance that has lead, for example, to the suicide of a hospitalised patient. Then, an action plan must be created in order to address identified problems. Yet, as reporting policies vary between countries, rigorous evaluation of many public reporting systems is still lacking (Fung et al., 2008; Tishler \& Reiss, 2009).

\section{SUICIDE RISK FACTORS IN CURRENT OR RECENTLY DISCHARGED PSYCHIATRIC INPATIENTS}

It has been argued that risk factors for suicidality in psychiatric in-patients are not necessarily the same as those for the general population (Powell et al., 2000). Risk factors can be divided into individual-level factors (history of suicidal behaviours, chronic mental illness - in particular affective and psychotic disorders -, presence of delusions, hopelessness, recent adverse life events - in particular bereavement -, co-morbid psychiatric disorders or physical illnesses, drug or alcohol abuse, history of sui-

Epidemiologia e Psichiatria Sociale, 19, 1, 2010 
cide in the family, male gender, unemployment, conflict with family members, etc.) and treatment-related factors (admission prompted by a suicide attempt, increased length of stay, medical non-compliance, multiple previous admits to hospital, poor ward atmosphere, frequent change of treatment approaches, rapidly fluctuating clinical course, etc.) (Sharma et al., 1998; Burgess et al., 2000; Deisenhammer et al., 2000; Powell et al., 2000; Wolfersdorf, 2000; Hoyer et al., 2004; Kapur et al., 2006; Combs \& Romm, 2007; Hunt et al., 2007; Yew Thong et al., 2008; Tishler \& Reiss, 2009). To date, there are no firm conclusions on whether involuntary hospitalization increases the risk for suicide (Meehan et al., 2006). While all the above suicide risk factors show a strong statistical association with suicide, they lack sufficient sensitivity to accurately predict the likelihood of a suicidal outcome. This consideration has lead some studies to rather focus on dynamic factors which would acutely increase the risk for suicide, such as severe anxiety and anhedonia (Tishler \& Reiss, 2009), medication non-compliance, loss of social support, and increased insight and awareness illness and its social consequences (Cassells et al., 2005).

The majority of in-patient suicides (from 53\% to 74\%) occurs outside the hospital, while the patient is on leave or has absconded (Cheung, 1992; Hunt et al., 2007; Powell et al., 2000; Shah \& Ganesvaran, 2001), with these percentages reaching over $90 \%$ in patients placed in open wards (Deisenhammer et al., 2000). Several authors have raised particular concerns about psychiatric patients granted unwarranted leave while still at high risk of suicide (Appleby et al., 1999; Wolfersdorf, 2000). Meehan et al. (2006) further reported that $72 \%$ of patients were on low level of observation at the time of death, based on staff's judgment that they were at no or low risk of suicide. A smaller, but still considerable, number of patients have committed suicides while on high-level monitoring, and some even during continuous one-to-one observation (Appleby et al., 1999; Powell et al., 2000; Busch et al., 2003). This would mean that sometimes even the strictest preventative measures do not suffice or, more often, are not implemented rigorously enough. Indeed, rather than the assessment results, the decision about a particular patient's level of suicide risk and frequency of needed observation is often influenced by the number of staff working on a particular unit (Wysocker, 1999), or by the presence of no-suicide contracts, despite dubious reports on their effectiveness (Busch et al., 2003). Burgess et al. (2000), in their audit of suicides among psychiatric service users, found that in $59 \%$ of cases suicide risk was not adequately ascertained or its level not given due weight.
Methods of suicide in psychiatric in-patients depend on whether the patient is on or off unit at time of death, and are influenced by the availability of means. For example, substances employed to overdose are usually unavailable in sufficient quantities for an in-patient, so this method is used less commonly that in general population (Combs \& Romm, 2007). Suicides in psychiatric wards are most commonly performed by hanging, while off-ward suicides are often completed also by other violent means, such as jumping from a height or leaping in front of a moving vehicle (Meehan et al., 2006; Hunt et al., 2007). Proximity of a road with heavy traffic, railway station or a river has been noted to influence the distribution of chosen methods (Morgan \& Priest, 1991; De Leo \& Krysinska, 2008).

Two sharp peaks of risk for suicide surrounding psychiatric hospitalizations have been observed - one in the first week after admission (Blain \& Donaldson, 1995; Qin \& Nordentoft, 2005), and another shortly after discharge (Hunt et al., 2007; Meehan et al., 2006), or even on the actual day of discharge (Deisenhammer et al., 2007). General suicide risk factors fail to explain why almost $40 \%$ of suicide deaths in recently discharged patients occur before the first follow-up appointment, suggesting the existence of an additional and more specific set of risk factors for this population (Meehan et al., 2006). In Appleby's opinion (2000), special circumstances that may increase suicide risk at discharge are:

1) incomplete recovery, which may lead to quick deterioration of mental state;

2) return of insight, which may bring a depressing awareness of the illness' consequences;

3) abrupt withdrawal of treatment, which may enhance vulnerability;

4) re-exposition to the stressors which precipitated admission; and,

5) easier access to means of suicide.

Available evidence has also pinpointed significant increases in suicide risk in connection to disruptions in post-discharge outpatient services, such as case-manager absence (Kan et al., 2007; King et al., 2001). Additional post-discharge specific risk factors that have been noted are: short duration of in-patient care, first admission, refused or delayed access to treatment and staffing/organisational changes, poor relationship with treatment team, and withdrawal from treatment against medical advice (Appleby et al., 1999; Burgess et al., 2000; Qin \& Nordentoft, 2005; Cooper et al., 2006).

Epidemiologia e Psichiatria Sociale, 19, 1, 2010 


\section{PREVENTION OF IN-PATIENT SUICIDE}

It is unrealistic to believe that all suicides could ever be prevented; however, as in-patient suicides occur in the physical context of mental health care, they should be the most amenable to prevention by psychiatric services (Hunt et al., 2007). Most commonly suggested preventative approaches include: better recognition and continuous monitoring of individual's risk for suicide (Tishler \& Reiss, 2009); effective treatment of underlying mental disorders (Appleby, 2000); appropriate ward design (Wolfersdorf, 2000); and, improved follow-up of discharged patients and their careful transition into community-based care (Burgess et al., 2000). Yet, while these approaches carry strong potential to reduce the incidence of in-patient suicides, an evaluation of their translation into practice is still missing.

There have been a few attempts at developing models with sufficient sensitivity to predict risk of suicide in psychiatric patients (Powell et al., 2000; Spiessl et al., 2002), but the small number of actual suicides hinders their reliability (De Leo \& Heller, 2007). Therefore, for the time being, we should stress the need for more stringent assessment and monitoring of patients' risk for selfharm. Compliance to clinical guidelines for the management of suicidal patients can be improved by active implementations of standards of care through enhanced staff education and regular feedback on their performance (Forsner et al., 2008). More attention should also be placed on sub-optimal staff-patient relationships, which Burgess et al. (2000) found to be the most common factor in inadequate assessment of patients. Lack of confidence in own technical preparation and professional skills is significant because - as Patterson et al. (2007) argued - clinicians who do not possess sufficient capabilities may actually contribute to the dynamic risk factors for suicide. Also, Tishler \& Reiss (2009) suggested that staff should more rigorously monitor behavioural signs and symptoms, and gather information from collateral sources, rather than rely solely on self-reported indicators of patient's improvements. Similarly, Simon \& Gutheil (2009) caution against the possibility of feigned recovery of patients, who may deny having suicidal thoughts in order to accelerate their discharge from hospital. Indeed, too often clinicians rely on the presumed absence of a suicide plan and under-rate the actual risk of suicide, not realising that those patients that are determined to commit suicide may want to hide their intention to avoid being prevented in doing so.

Several programs have been designed aiming to deepen clinician's understanding and confidence when presented with self-harming patients (e.g. Patterson et al., 2007; McAllister et al., 2009). Continuous observation protocols for at-risk patients have been suggested as another important approach to preventing inpatient suicides, with the American Psychiatric Association's Practice Guidelines for the Assessment and Treatment of Patients with Suicidal Behaviors advising that the level of suicide precautions needs to be based on an adequate risk assessment and a clinical rationale (Jacobs et al., 2003). However, Janofsky (2009) observed that to date no systematic studies nor practical recommendation have been developed for best observation practices, and that miscommunication between staff is the most common precipitating factor leading to failure in provision of such monitoring. Lieberman et al. (2004) suggested that periodic checks should be done in a variable, unpredictable fashion and that constant, arm-length observation is one of the most effective ways to protect high-risk individuals. On the other hand, authors also recognised several obstacles preventing realisation of the suggested approaches, mainly as a result of economic pressure placed on inpatient units.

Appleby et al. (1999) hypothesised that a substantial percentage of in-patient suicides occur in wards because of their unsuitableness for the care of acutely ill patients. The physical environment of psychiatric units undoubtedly plays a major role in effective treatment; therefore, while conceived to induce stabilizing and comforting effects, their architectural design would need to be 'suicide proofed'. Several recommendations have been developed to achieve that: for example by securing open areas to prevent absconding, removing items that can be used as hanging or cutting devices and locating wards at some distance from tall structures or main roads (Appleby, 2000; Lieberman et al., 2004). Yet, despite the fact that the physical environment of in-patient units is frequently identified as a root cause of suicide, this area of investigation remains under-explored (Lieberman et al., 2004).

Assuring better continuity of care is compulsory, particularly when increasing demand on in-patient services may lead to untimely discharge of patients who are still at moderate or even high risk of suicide (Hoyer et al., 2004; Qin \& Nordentoft, 2005). It has been estimated that the implementation of timelier outreach interventions within the first seven days from discharge could prevent about $20 \%$ of total suicides (Burgess et al., 2000). However, even when such interventions are available to balance the risks arising from premature discharge, patients are often reluctant to participate in

Epidemiologia e Psichiatria Sociale, 19, 1, 2010 
treatments, with half of discharged patients refusing offered follow-up services (Motto \& Bostrom, 2001), and dropout rates increasing up to $77 \%$ at three months post discharge (Meehan et al., 2006). Therefore, Crawford (2004) suggested that it may be more profitable to concentrate resources on the development and implementation of more assertive follow-up for all discharged patients, rather than attempting to determine their risks at discharge, or focus only on patients known to be at highest risk. In line with these observations, a WHO World Health Report on mental health urged that "care should shift away from large psychiatric hospitals to community services that are integrated into general health services" (World Health Organization, 2001, p. 75). While several types of community-care services alternative to conventional in-patient care have been developed, such as 'acute' day hospitals, crisis houses and home treatment/crisis resolution teams (Thornicroft \& Tansella, 2004), their effectiveness is yet to be conclusively demonstrated (Lloyd-Evans et al., 2009).

\section{CONCLUSIONS}

The suicide of a psychiatric patient, especially when it occurs in a purportedly safe hospital environment, has many far-reaching effects, and often elicits intense emotional responses in staff, hospital administration, other patients and the deceased patient's family and friends (Hodelet \& Hughson, 2001). Several risk factors for suicide seem to be peculiar of psychiatric in-patients. Notwithstanding the poor accuracy in predicting suicidal outcomes, there are ample opportunities for improving the management of suicidal patients in hospital wards. The decision to hospitalise is an important one and should never be taken light-hearted: it is a medical act that carries both clinical and human consequences. Selfdefensiveness on the side of physicians (an 'enlargement' of the 'better safe than sorry' principle) should not be the main inspiring motive for admitting to a psychiatric ward. In the real world, a careful balancing between severity of suicidal risk, bed availability, opportunities for rehabilitation, financial pressures and expected outcomes should be able to drive the right decision. Then, better continuity of care for recently discharged psychiatric patients cannot be overstated; neither can we underestimate the need for development of efficient community-based services, which would disburden the overcrowded psychiatric units, allowing for greater attention to be paid to environmental risk factors.

\section{REFERENCES}

American Psychiatric Association (1994). Diagnostic and Statistical Manual of Mental Disorders (DSM-IV), 4th Ed. American Psychiatric Press: Washington.

Appleby L. (2000). Prevention of suicide in psychiatric patients. In The International Handbook of Suicide and Attempted Suicide (ed. K. Hawton and K. van Heeringen), pp. 617-630. John Wiley \& Sons: West Sussex.

Appleby L., Dennehy J.A., Thomas C.S., Faragher E.B. \& Lewis G. (1999). Aftercare and clinical characteristics of people with mental illness who commit suicide: a case-control study. Lancet 353, 13971400.

Arsenault-Lapierre G., Kim, C. \& Turecki G. (2004). Psychiatric diagnoses in 3275 suicides: a meta-analysis. BMC Psychiatry 4, 37.

Bertolote J.S., Fleischmann A., De Leo D. \& Wasserman D. (2003). Suicide and mental disorders: do we know enough? British Journal of Psychiatry 183, 382-383.

Bertolote J.M., Fleischmann A., De Leo D. \& Wasserman D. (2004). Psychiatric diagnoses and suicide: Revisiting the evidence. Crisis 25, 147-155.

Blain P.A. \& Donaldson L.J. (1995). The reporting of in-patient suicides: identifying the problem. Public Health 109, 293-301.

Burgess B., Pirkis J., Morton J. \& Croke E. (2000). Lessons from a comprehensive clinical audit of users of psychiatric services who committed suicide. Psychiatric Services 51, 1555-1560.

Busch K.A, Fawcett J. \& Jacobs D.G. (2003). Clinical correlates of inpatient suicide. Journal of Clinical Psychiatry 64, 14-19.

Cassells C., Paterson B., Dowding D. \& Morrison R. (2005). Long- and short-term risk factors in the prediction of inpatient suicide: A review of the literature. Crisis 26, 53-63.

Cavanagh J.T.O., Carson A.J., Sharpe M. \& Lawrie S.M. (2003). Psychological autopsy studies of suicide: A systematic review. Psychological Medicine 33, 395-405.

Cheung P. (1992). Suicide precautions for psychiatric inpatients: a review. Australian and New Zealand Journal of Psychiatry 26, 592598.

Combs H. \& Romm S. (2007). Psychiatric inpatient suicide: a literature review. Primary Psychiatry 14, 67-74.

Cooper S., Lezotte D., Jacobellis J. \& Diguiseppi C. (2006). Does availability of mental health resources prevent recurrent suicidal behavior? Suicide and Life-Threatening Behavior 36, 409-417.

Crawford M., (2004). Suicide following discharge from in-patient psychiatric care. Advances in Psychiatric Treatment 10, 434-438.

De Leo D. \& Heller T. (2007). Intensive case management in suicide attempters following discharge from inpatient psychiatric care. Australian Journal of Primary Health 13, 49-59.

De Leo D. \& Krysinska K. (2008). Suicidal behaviour by train collision in Queensland, 1990-2004. Australian and New Zealand Journal of Psychiatry 42, 772-779.

Deisenhammer E.A., DeCol C., Honeder M., Hinterhuber H. \& Fleischhacker W.W. (2000). In-patient suicide in psychiatric hospitals. Acta Psychiatrica Scandinavica 102, 290-294.

Deisenhammer E.A., Huber M., Kemmler G., Weiss E.M. \& Hinterhuber H. (2007). Psychiatric hospitalizations during the last 12 months before suicide. General Hospital Psychiatry 29, 63-65.

Eklund M. (1996). Working relationship, participation, and outcome in a psychiatric day care unit based on occupational therapy. Scandinavian Journal of Occupational Therapy 3, 106-113.

Fergusson D.M., Horwood J., Ridder E.M. \& Beautrais A.L. (2005). Subthreshold depression in adolescence and mental health outcomes in adulthood. Archives of General Psychiatry 62, 66-72.

Forsner T., Wistedt A.A., Brommels M. \& Forsell Y. (2008). An approach to measure compliance to clinical guidelines in psychiatric care. BMC Psychiatry 8, 84-72.

Fung C.H., Lim Y.W., Mattke S., Damberg C. \& Shekelle P.G. (2008). Systematic review: the evidence that publishing patient care perfor-

Epidemiologia e Psichiatria Sociale, 19, 1, 2010 
mance data improves quality of care. Annals of Internal Medicine $148,111-123$

Goldberg J.F., Ernst C.L. \& Bird S. (2007). Predicting hospitalization versus discharge of suicidal patients presenting to a psychiatric emergency service. Psychiatric Services 4, 561-565.

Gowers S.G. \& Rowlands L. (2005). Inpatient services. Current Opinion in Psychiatry 18, 445-448.

Harris E.C. \& Barraclough B. (1997). Suicide as an outcome for mental disorders: a meta-analysis. British Journal of Psychiatry 170, 205-228.

Hodelet N. \& Hughson M. (2001). What to do when a patient commits suicide. Psychiatric Bulletin 25, 43-45.

Holcomb W.R., Parker J.C., Leong G.B., Thiele J. \& Higdon J. (1998). Customer satisfaction and self-reported treatment outcomes among psychiatric inpatients. Psychiatric Services 49, 929-934.

Hoyer E.A., Olesen A.V. \& Mortensen P.B. (2004). Suicide risk in patients hospitalised because of an affective disorder: a follow-up study, 1973-1993. Journal of Affective Disorders 78, 209-217.

Huband, N. \& Tantam, D. (2000) Attitudes to self-injury within a group of mental health staff. British Journal of Medical Psychology 73, 495-504.

Hunt I.M., Kapur N., Webb R., Robinson J., Burns J., Turnbull P., Shaw J. \& Appleby L. (2007). Suicide in current psychiatric in-patients: a case-control study: the national confidential inquiry into suicide and homicide. Psychological Medicine 37, 831-837.

Jacobs D.G., Baldessarini R.J., Conwell Y., Fawcett J.A., Horton L., Meltzer H., Pfeffer C.R. \& Simon R.I. (2003). Practice guideline for the assessment and treatment of patients with suicidal behaviors. American Journal of Psychiatry 160, 1- 60.

Janofsky J.S. (2009). Reducing inpatient suicide risk: using human factors analysis to improve observation practices. Journal of the American Academy of Psychiatry and the Law 37, 15-24.

Jones A. \& Crossley D. (2008). 'In the mind of another' shame and acute psychiatric inpatient care: an exploratory study. A report on phase one: service users. Journal of Psychiatric and Mental Health Nursing 15, 749-757.

Johannessen H.A., Dieserud G., Jakhelln F., Zahl P.H. \& De Leo D. (2009). Changes in institutional psychiatric care and suicidal behaviour: a follow-up study of inpatient suicide attempters in Baerum, Norway. Social Psychiatry and Psychiatric Epidemiology 44, 845851.

Joint Commission on Accreditation of Healthcare Organization (2009). Sentinel event policy and procedures. Retrieved December 15 2009, from http://www.jointcommission.org/SentinelEvents/ PolicyandProcedures/

Kaltiala-Heino R. (2009). Involuntary commitment and detainment in adolescent psychiatric inpatient care. Social Psychiatry and Psychiatric Epidemiology. Published online: 19 August 2009. doi: 10.1007/s00127-009-0116-3.

Kan C.K., Ho T.P., Dong J.Y. \& Dunn E.L. (2007). Risk factors for suicide in the immediate post-discharge period. Social Psychiatry and Psychiatric Epidemiology 42, 208-214.

Kapur N., Hunt I.M., Webb R.W., Bickley H., Windfuhr K., Shaw J. \& Appleby L. (2006). Suicide in psychiatric in-patients in England, 1997 to 2003. Psychological Medicine 36, 1485-1492.

King E.A., Baldwin D.S., Sinclair J.M.A., Baker N., Campbell M.J. \& Thompson C. (2001). The Wessex recent in-patient suicide study 1 : case-control study of 234 recently discharged psychiatric patient suicides. British Journal of Psychiatry 178, 531-536.

Lieberman D.Z., Resnik H.L.P. \& Holder-Perkins V. (2004). Environmental risk factors in hospital suicide. Suicide and Life Threatening Behavior 34, 448-453.

Lloyd-Evans B., Slade M., Jagielska D. \& Johnson S. (2009). Residential alternatives to acute psychiatric hospital admissions: systematic review. British Journal of Psychiatry 195, 109-117.

Lorant V., Depuydt C., Gillain B., Guillet A. \& Dubois V. (2007). Involuntary commitment in psychiatric care: what drives the decision? Social Psychiatry and Psychiatric Epidemiology 42, 360-365.
Luoma J.B., Martin C.E. \& Pearson J.L. (2002). Contact with mental health and primary care providers before suicide: a review of the evidence. American Journal of Psychiatry 159, 909-916.

Mann C.E. \& Himelein M.J. (2004). Factors associated with stigmatization of persons with mental illness. Psychiatric Services 55, 185 187.

Mathers C.D. \& Loncar D (2006). Projections of global mortality and burden of disease from 2002 to 2030. PLoS Medicine 3, e442.

McAllister M., Moyle W., Billett S. \& Zimmer-Gembeck M. (2009). 'I can actually talk to them now': qualitative results of an educational intervention for emergency nurses caring for clients who self-injure. Journal of Clinical Nursing 18, 2838-2845.

Meehan J., Kapur N., Hunt I.M., Turnbull P., Robinson J., Bickley H., Parsons R., Flynn S., Burns J., Amos T., Shaw J. \& Appleby L. (2006). Suicide in mental health in-patients and within 3 months of discharge: national clinical survey. British Journal of Psychiatry $188,129-134$.

Mehlum L. (2009). Treatment of suicide attempts and suicidality in psychiatric care. In Oxford Textbook of Suicidology and Suicide Prevention: A Global Perspective (ed. D. Wasserman and C. Wasserman), pp. 471-476. Oxford University Press: New York.

Morgan H.G. \& Priest P. (1991). Suicide and other unexpected deaths among psychiatric inpatients: the Bristol confidential inquiry. British Journal of Psychiatry 158, 368-374.

Motto J. \& Bostrom A. (2001). A randomized controlled trial of postcrisis suicide prevention. Psychiatric Service 52, 828-833.

Nock M.K., Hwang I., Sampson N., Kessler R.C., Angermeyer M., Beautrais A., Borges G., Bromet E., Bruffaerts R., de Girolamo G., de Graaf R., Florescu S., Gureje O., Haro J.M., Hu C., Huang Y., Karam E.G., Kawakami N., Kovess V., Levinson D., Posada-Villa J., Sagar R., Tomov T., Viana M.C. \& Williams D.R. (2009). Crossnational analysis of the associations among mental disorders and suicidal behavior: findings from the WHO World Mental Health Surveys. PLoS Medicine. Published online: 11 August 2009. doi:10.1371/journal.pmed.1000123.

Paris J. (2007). Half in Love with Death: Managing the Chronically Suicidal Patient. Lawrence Erlbaum Associated: Mahwah, NJ.

Patterson P., Whittington R. \& Bogg J. (2007). Testing the effectiveness of an educational intervention aimed at changing attitudes to selfharm. Journal of Psychiatric and Mental Health Nursing 14, 100-105.

Pirkola S., Sohlman B., Heilä H. \& Wahlbeck K. (2007). Reductions in post-discharge suicide after deinstitutionalization and decentralization: a nationwide register study in Finland. Psychiatric Services 58, 221-226.

Powell J., Geddes J., Deeks J., Goldacre M. \& Hawton K. (2000). Suicide in psychiatric hospital in-patients: risk factors and their predictive power. British Journal of Psychiatry 176, 266-272.

Qin P. \& Nordentoft M. (2005). Suicide risk in relation to psychiatric hospitalization: evidence based on longitudinal registers. Archives of General Psychiatry 62, 427-432.

Ritsher J.B. \& Phelan J.C. (2004). Internalized stigma predicts erosion of morale among psychiatric outpatients. Psychiatry Research 129 , 257-265.

Rosenhan D.L. (1973). On being sane in insane places. Science, 250-258.

Salize H.J. \& Dressing H. (2004). Epidemiology of involuntary placement of mentally ill people across the European Union. British Journal of Psychiatry 184, 163-168.

Saxena S., Thornicroft G., Knapp M. \& Whiteford H. (2007). Resources for mental health: scarcity, inequity, and inefficiency. Lancet 370 , $878-889$.

Shah A. \& Ganesvaran T. (2001). Completed suicide among psychiatric in-patients with depression in an Australian mental hospital. International Journal of Methods in Psychiatric Research 9, 25-31.

Sharma V., Persad E. \& Kueneman K. (1998). A closer look at inpatient suicide. Journal of Affective Disorders 47, 123-129.

Simon R. \& Gutheil T.G. (2009). Sudden improvement among highrisk suicidal patients: should it be trusted? Psychiatric Services 60, 387-389.

Epidemiologia e Psichiatria Sociale, 19, 1, 2010 
Spiessl H., Hubner-Liebermann B. \& Cording C. (2002). Suicidal behaviour of psychiatric in-patients. Acta Psychiatrica Scandinavica 106, 134-138.

Tanney, B.L. (2000). Psychiatric diagnoses and suicidal acts. In Comprehensive Textbook of Suicidology (ed. R.W. Maris, A.L. Berman and M.M. Silverman), pp. 311-341. Guilford Press: New York.

Thornicroft G. \& Tansella M. (2004). Components of a modern mental health service: a pragmatic balance of community and hospital care: overview of systematic evidence. British Journal of Psychiatry 185 , 283-290.

Tidemalm D., Waern M., Stefansson C.-G., Elofsson S. \& Runeson B. (2008). Excess mortality in persons with severe mental disorder in Sweden: a cohort study of 12103 individuals with and without contact with psychiatric services. Clinical Practice and Epidemiology in Mental Health 4, 23-31.

Tishler C.T. \& Reiss N.S. (2009). Inpatient suicide: preventing a common sentinel event. General Hospital Psychiatry 31, 103-109.

Traskman-Bendz L. \& Sunnqvist C. (2009). A specialized inpatient unit for suicidal patients: dvantages and disadvantages. In Oxford Textbook of Suicidology and Suicide Prevention: A Global Perspective (ed. D. Wasserman and C. Wasserman), pp. 477-482. Oxford University Press: New York.

Välimäki M., Taipale J. \& Kaltiala-Heino R. (2001). Deprivation of liberty in psychiatric treatment: a Finnish perspective. Nursing Ethics $8,522-532$.
Van Egmond N. \& Diekstra R.F. (1990). The predictability of suicidal behavior: the results of a meta-analysis. Crisis 11, 57-84.

Webber M. \& Huxley P. (2004). Social exclusion and risk of emergency compulsory admission: A case-control study. Social Psychiatry and Psychiatric Epidemiology 39, 1000-1009.

Williams L. (1998). A 'classic' case of borderline personality disorder. Psychiatric Services 49, 173-174.

Wingate L.R., Joiner T.E., Walker R.L., Rudd M.D. \& Jobes D.A (2004). Empirically informed approaches to topics in suicide risk assessment. Behavioral Sciences and the Law 22, 651-665.

Wittchen H.U. \& Jacobi F. (2005). Size and burden of mental disorders in Europe: a critical review and appraisal of 27 studies. European Neuropsychopharmacology 15, 357-336.

Wolfersdorf M. (2000). Suicide among psychiatric inpatients. In The International Handbook of Suicide and Attempted Suicide (ed. K. Hawton and K. van Heeringen), pp. 457-466. John Wiley \& Sons: West Sussex.

World Health Organization (2001). The World Health Report, 2001. Mental Health: New Understanding, New Hope. WHO: Geneva.

Wysocker A. (1999). Suicide: risk management strategies. Journal of the American Psychiatric Nurses Association 5, 164-166.

Yew Thong J., Hc Su A., Huak Chan Y. \& Hock Chia B. (2008). Suicide in psychiatric patients: case-control study in Singapore. Australian and New Zealand Journal of Psychiatry 42, 509519. 